\title{
An international, multi-centre, observational study of fluid bolus therapy in neonates
}

Type of manuscript: Original Article

Authors: AK Keir ${ }^{1,2,3}$, O Karam ${ }^{4,5}$, N Hodyl ${ }^{1,2}$, MJ Stark ${ }^{1,2}$, HG Liley ${ }^{6,7}$, PS Shah ${ }^{8,9}$ and SJ Stanworth ${ }^{10,11}$ on behalf of the NeoBolus Study Group

Affiliations:

1. Robinson Research Institute and the Adelaide Medical School, University of Adelaide

2. Department of Neonatal Medicine, Women's and Children's Hospital, North Adelaide, South Australia

3. Healthy Mothers, Babies and Children, the South Australian Medical and Research Institute, North Adelaide, South Australia

4. Pediatric Intensive Care Unit, Geneva University Hospital, Geneva, Switzerland

5. Division of Pediatric Critical Care Medicine, Children's Hospital of Richmond at VCU, Virginia Commonwealth University, Virginia, USA

6. Mater Mothers' Hospital, Mater Research, Brisbane, Queensland, Australia

7. The University of Queensland, South Brisbane, Queensland, Australia

8. Mount Sinai Hospital, Toronto, Ontario, Canada

9. University of Toronto, Toronto, Ontario, Canada

10. NHS Blood and Transplant and Department of Haematology, Oxford University Hospitals NHS Foundation Trust, Oxford, United Kingdom

11. Radcliffe Department of Medicine, University of Oxford, Oxford, United Kingdom

\section{Corresponding author:}

Dr Amy Keir

Women's and Children's Hospital

72 King William Road

North Adelaide SA 5006

AUSTRALIA

Phone: +61881617631

Fax: +6181617654

Email: amy.keir@adelaide.edu.au

\section{What is already known on this topic}

Fluid bolus therapy is used for the management of haemodynamic compromise in neonates.

This is the author manuscript accepted for publication and has undergone full peer review but has not been through the copyediting, typesetting, pagination and proofreading process, which may lead to differences between this version and the Version of Record. Please cite this article as doi: $10.1111 /$ jpc.14260

This article is protected by copyright. All rights reserved. 
The indications for, the type of fluids used and the short-term clinical outcomes of fluid bolus therapy are poorly understood.

There is increasing evidence in paediatric medicine that fluid bolus therapy may be either ineffective or harmful.

\section{What this paper adds}

Our study suggests fluid bolus therapy remains a practice in preterm and term infants in neonatal units in highly resourced countries. The most common type of fluid used is $0.9 \%$ sodium chloride at $10 \mathrm{~mL} / \mathrm{kg}$ over 30 minutes.

The most common indications for fluid bolus therapy in neonates are low blood pressure, decreased perfusion on clinical assessment and a metabolic acidosis.

Current clinical trials in this area are focusing on the use of inotropes, however, fluid bolus therapy also warrants closer examination. This study provides key data to develop interventional trials.

This article is protected by copyright. All rights reserved. 


\section{Abstract and keywords}

Aims: To assess the prevalence, types, and indications for fluid bolus therapy in neonates with haemodynamic compromise.

Methods: A pragmatic international multi-centre observational study in neonatal units across Australasia, Europe, and North America. A pre-defined study period of 10-15 study days per participating neonatal unit between December 2015-March 2017. Infants d28 days of age who received a fluid bolus for the managment of haemodynamic compromise (e $10 \mathrm{ml} / \mathrm{kg}$ given at $\mathrm{d} 6$ hours) were included.

Results: 163 neonates received a bolus over 8479 eligible patient days in 41 neonatal units. Prevalence of fluid bolus therapy varied between centres from $0 \%$ to $28.6 \%$ of admitted neonates per day, with a pooled prevalence rate of $1.5 \%$ (95\% confidence interval 1.1-1.9\%). The most common fluid used was $0.9 \%$ sodium chloride (129/163; $79 \%)$, the volume of fluid administered was most commonly $10 \mathrm{~mL} / \mathrm{kg}(115 / 163$; $71 \%$ ) over a median of 30 (interquartile range 20-60) minutes. The most frequent indications were hypotension $(n=56 ; 34 \%)$, poor perfusion $(n=20 ; 12 \%)$ and metabolic acidosis $(n=20 ; 12 \%)$. Minimal or no clinical improvement was reported by clinicians in 66/163 (40\%).

Conclusions: Wide international variations in types, indications and effects of fluid bolus administration in haemodynamically compromised neonates suggest uncertainty in the risk-benefit profile. This is likely to reflect the lack of robust evidence to support the efficacy of different fluid types, doses and appropriate indications. Together, these highlight a need for further clinically relevant studies.

Keywords: infant, newborn; therapy, fluid; blood pressure. 


\section{Introduction}

Intravenous fluid bolus therapy for suspected haemodynamic compromise in neonates, with a variety of underlying conditions, is a common intervention in neonatal units. Fluid boluses may include crystalloids such as $0.9 \%$ sodium chloride, or colloids such as albumin or blood products including plasma, which have different biochemical properties. While this therapy represents an established component of the management of haemodynamic compromise in neonates, the volume, type of fluid, timing and indications for this practice are not well described or understood. ${ }^{1-3} \mathrm{~A}$ Cochrane review found no benefit from the use of early fluid bolus therapy in infants d 32 weeks gestation without haemodynamic compromise. ${ }^{1}$ This review identified no available evidence to determine whether those with clear haemodynamic compromise might benefit from volume expansion compared to no volume expansion. ${ }^{1}$ Another review, including two more recent studies not included in the previous meta-analysis, was again unable to establish any benefit from fluid bolus therapy in late preterm and term infants with signs of haemodynamic compromise. ${ }^{3}$ There are well documented concerns about the consequences of fluid bolus therapy in older children, but comparable data do not exist in neonates. It is possible that some fluid boluses provide no clinical benefit, and may even cause harm. ${ }^{4,5}$

As a first step in evaluating and improving the use of fluid bolus therapy in clinical practice, we conducted a pragmatic, international, multi-centre, observational study to explore existing practices of fluid bolus therapy. Our primary objective was to describe the prevalence, types, indications for and doses of fluid bolus therapy administered to neonates with suspected haemodynamic compromise. Secondary objectives were to determine variations in practice of fluid bolus therapy and evaluate the degree of perceived improvement post fluid boluses.

\section{Methods}

\section{Study design and setting}


This study was an international, pragmatic, multi-centre, observational study undertaken at 41 neonatal units in Australasia $(n=12)$, North America $(n=16)$ and Europe $(n=13)$. Units were recruited through neonatal research networks and specialty societies, as well as through personal communications directed by the main study investigators. Participating neonatal units collected data in blocks of 5 continuous days in 2-3 blocks for a minimum of 10 days and up to a maximum of 15 days per unit. This was a pragmatic decision, given limited study funding, to allow units to support a period of study data collection, based (for example) on availability of local research staff or individuals. Data collection occurred between December 2015 and March 2017.

\section{Participants}

Newborn infants of any gestation at birth who were $\mathrm{d} 28$ days of age who received a fluid bolus for suspected haemodynamic compromise were included. Participants were identified by the individual study site co-investigators.

\section{Exposure}

The exposure of interest was a fluid bolus given for the purposes of intravascular volume expansion for suspected haemodynamic compromise. Fluids included were $0.9 \%$ sodium chloride, $0.45 \%$ sodium chloride, Ringer's lactate solution, albumin, frozen plasma, whole blood or RBCs. The fluid bolus had to be $10 \mathrm{~mL} / \mathrm{kg}$ or greater volume given over $\mathrm{d} 6$ hours. Neonates who received bolus fluids for hypoglycaemia or RBC transfusions to manage anaemia of prematurity alone were excluded.

\section{Variables}

Demographic and clinical characteristics of included neonates and participating units were collected. We collected information on type, volume and duration of bolus fluids administered. Information on indications for fluid boluses assigned according to predefined categories, including an "other" category where site investigator was asked to define the indication were collected; see Supplementary material 1 for the data 
collection sheet. The effects of fluid boluses on short-term perceived clinical outcomes at 4-6 hours after administration were categorized according to a numerical score. These scores were based on clinician report 4-6 hours post-bolus in 4 areas: (1) the reported degree of improvement in the primary indication for fluid (no change $=0$, some improvement $=1$, large improvement $=2$ ), (2) the need for escalation of therapy to inotrope use (new agent started $=0$, one or more agents increased and one or more agents decreased $=1$, or no agent started, agent decreased or stopped=2), (3) additional fluids bolus(es) within six hours of the first (more than $2=0$, one additional bolus $=1$, no additional bolus $=2$ ) and $(4)$ whether another treatment e.g. sodium bicarbonate infusion or blood products was received for the primary indication (yes $=0, n_{0}=2$ ). These scores were summed and classified as no or minor improvement (score $0-2$ ), mild improvement (score 3-5) or major improvement (6-8). The scoring sheet is provided in Supplementary material 1 and was developed by expert consensus and a formal piloting process, including neonatologists, paediatric critical care and haematologists within the study group.

\section{Data management}

Study data were collected and managed using the Research Electronic Data Capture (REDCap) tools hosted at the University of Adelaide, Australia. ${ }^{6}$ REDCap is a secure, web-based application designed to support data capture for research studies, providing 1) an interface for validated data entry; 2) audit trails for tracking data manipulation and export procedures; 3 ) automated export procedures for data downloads to common statistical packages; and 4) procedures for importing data from external sources.

\section{Data sources}

Descriptive data on unit characteristics were collected by individual study site coordinators, including type of unit, country, number of neonates admitted per year, availability of unit guidelines for fluid bolus and/or RBC transfusion. 


\section{Sample size}

All infants in each participating institution who received at least one fluid bolus during the site collection period were included in the study. A sample of 41 units agreed to participate. Each patient was enrolled only once for the first bolus received during the study interval even if he/she received further boluses on a subsequent study day.

\section{Statistical analysis}

Normally distributed data were described by the mean and standard deviation (SD) and non-normally distributed data using the median and interquartile range (IQR). Analyses were carried out using $\mathrm{R}$ statistical software package ( $\mathrm{R}$ version 3.1.0 (2014-04-10) ${ }^{7}$ unless otherwise specified. Prevalence rate for receipt of bolus was calculated by dividing number of neonates who received a bolus by the number of neonates who were present in the unit during the study interval who were $\leq 28$ days of age. Each neonate on a given day was considered to be eligible to receive a bolus until the study period ended. Pooled prevalence rate and 95\% confidence interval were calculated using Der-simonian random-effects model with open access Meta-analyst software. ${ }^{8}$

\section{Ethics approval}

Site specific ethics approval was obtained for all sites. Two centres in Canada required individual written consent prior to collection of clinical data. French and Swiss sites had an opt-out strategy with information provided for families in the units' waiting rooms. All other ethics committees waived the requirement for individual consent given that all data were routinely collected for clinical purposes and no individual identifying data would be recorded and sent to the lead site. 


\section{Results}

\section{Participating centres}

Forty-one units participated in the study. Ten (24\%) were in Australia, eight (20\%) in Canada, four (10\%) in France, one (2\%) in Italy, two (5\%) in New Zealand, one (2\%) in Portugal, four (10\%) in Sweden, two (5\%) in Switzerland, one (2\%) in the United Kingdom and eight $(20 \%)$ in the USA. Median numbers of admissions per unit per year were 650 (IQR 420 -1836). Twenty-two (55\%) units were classified as general perinatal centres, $16(39 \%)$ were surgical units including cardiac and three (7.5\%) were mixed (NICU/PICU) units.

\section{Patient characteristics}

A total of 163 neonates received a bolus over 8479 eligible patient days. Pooled prevalence rate of receipt of fluid bolus was 1.5\% (95\% confidence interval 1.1$1.9 \%$;) across all participating units. Prevalence of bolus administration in participating units varied from $0 \%$ to $28.6 \%$ of admitted neonates ( 228 days of age) per day. Data for individual units, grouped by geographical regional area, are provided in Figure 1.

For included infants, the birth gestation of included infants reflected a bimodal distribution with peaks at 27 and 39 weeks (Figure 2) as did birthweight with peaks at 650-850 grams and 2850-3050 grams. The majority of neonates received their first fluid bolus on the day of birth $(87 / 163 ; 53 \%)$, and there was diminishing likelihood of a first fluid bolus on subsequent days; day 2 (24/163; 15\%), days 3-7 (25/163; 15\%) and $>7$ days $(27 / 163 ; 17 \%)$. The reported primary indications for fluid bolus therapy are provided in Table 1.

\section{Clinical guideline availability}

Local clinical practice guidelines which referenced fluid bolus therapy were available in only $10(24 \%)$ of the participating units.

This article is protected by copyright. All rights reserved. 


\section{Fluid bolus characteristics}

Types of fluid used for fluid bolus therapy included $0.9 \%$ sodium chloride $(n=129$; $79 \%)$, RBCs $(n=15 ; 9 \%), 4$ or $5 \%$ albumin $(n=5 ; 3 \%)$, Ringer's lactate $(n=9 ; 5 \%)$, frozen plasma $(n=4 ; 3 \%)$ and $0.45 \%$ sodium chloride $(n=1 ;<1 \%)$. The commonest volume administered was $10 \mathrm{~mL} / \mathrm{kg}(\mathrm{n}=115 ; 67 \%)$ with a median duration of administration of 30 (IQR 20-60) minutes. Table 2 shows a breakdown of the indication for each fluid bolus and type of fluid used.

\section{Short-term outcomes}

Mortality

At the end of the data collection period 151/163 (93\%) of infants were alive. None of the infants died during the receipt of the fluid bolus or within 6 hours post-bolus.

\section{Clinician-perceived improvement}

Clinicians perceived no or minor improvement (score 0-2) in 25/163 (15\%), a mild improvement (score 3-5) in 41/163 (25\%) and a major improvement in 97/163 (60\%) in response to bolus therapy. Improvement according to primary indication is reported in Table 1. Table 3 (Supplementary material 2) provides further breakdown of indication for fluid bolus, type of fluid used and clinical improvement scores.

\section{Laboratory indices}

The following changes in laboratory parameters were observed following fluid bolus: pH 0.03 units (IQR; -0.03 to 0.12 units; $\mathrm{n}=140$ ) (Figure 3); lactate $-0.59 \mathrm{mmol} / \mathrm{L}$ $(-2.15$ to $0.02 \mathrm{mmol} / \mathrm{L} ; \mathrm{n}=100)$ (Figure 4); bicarbonate $0 \mathrm{mmol} / \mathrm{L}(-1.35$ to 2.00 $\mathrm{mmol} / \mathrm{L} ; \mathrm{n}=139)$; chloride $0.5 \mathrm{mmol} / \mathrm{L}$ (-1.00 to $3.00 \mathrm{mmol} / \mathrm{L} ; \mathrm{n}=80)$; base deficit $1.10 \mathrm{mmol} / \mathrm{L}(-3.93$ to $1.00 \mathrm{mmol} / \mathrm{L} ; \mathrm{n}=128)$ and haemoglobin $-5.00 \mathrm{~g} / \mathrm{L}(-16.00$ to $9.25 \mathrm{~g} / \mathrm{L} ; \mathrm{n}=88)$.

\section{Variations in prevalence of fluid bolus therapy}

Regions 
The pooled prevalence for fluid bolus therapy for Australian and New Zealand units $(\mathrm{n}=12)$ was $1.2 \%$ (95\% CI 0.6-1.7\%;), in Canadian units $(\mathrm{n}=8)$ it was $1.5 \%(95 \%$ CI $0.8-2.1 \%)$, in USA-based units $(\mathrm{n}=9)$ it was $1.8 \%(95 \%$ CI 0.8-2.8\%) and in European units $(\mathrm{n}=12)$ it was $2.7 \%(95 \%$ CI 1.1-4.4\%) (Figure 1$)$.

\section{Types of centre}

The pooled prevalence for fluid bolus therapy within general perinatal centres $(n=22)$ was $1.3 \%$ (95\% CI $0.9-1.8 \%)$ and within the remaining centres (surgical and mixed units) $(\mathrm{n}=19)$ it was $1.9 \%(95 \%$ CI 1.2-2.6\%). The centre with the highest prevalence rate was a non-perinatal unit caring primarily for paediatric patients.

\section{Discussion}

This international study explored the prevalence, types, and indications of fluid bolus therapy in neonates with haemodynamic compromise. This was a pragmatic study, aimed at trying to better define the current practices of fluid bolus therapy, and as such was developed with the need to be very restrictive on the amount of data collection. While the pooled prevalence rate was low, the prevalence of this therapy varied $(0 \%$ to $28.6 \%)$. We identified variations in the nominated indications for and frequency of use of fluid boluses between participating units. Overall, perceived improvement following fluid bolus therapy was reported in $85 \%$ of cases.. Together, these results highlight a clear lack of consistent clinical approach and perceptions of variable effects.

The interpretation of our pragmatic study needs to recognise strengths and limitations. Our study was supported by a large number of units across many different countries. It describes practices in units that were selected by personal approaches by the investigators but we cannot assume they are representative of non-participating neonatal units and other countries. Participation was voluntary and units selected the most convenient time to support data collection. The calculation of incidence was based on the assumption that the prevalence of fluid boluses over the short study 
intervals was constant and representative of standard practice in each unit. This assumption may not be true. However, variations from the reported rate could be on either side of estimated rate and thus overall, the averaged results could be considered representative. In attempt to maximise unit participation, data collection was kept to a minimum, and therefore a number of outcomes of potential interest were not requested, for example blood pressure. In addition, it was not possible to collect detailed information on potential adverse effects related to fluid bolus beyond the six hours, such as volume overload, dilutional coagulopathy, hypothermia and electrolyte disturbances. ${ }^{4,9}$ This lack of data extends to other specific fluid related complications, including transfusion reactions, ${ }^{10,11}$ or $0.9 \%$ sodium chloride-induced hypochloremic metabolic acidosis, although we did not observe any significant increase in chloride level post-fluid bolus. We did not observe any significant changes in measured laboratory indices post-bolus. Reported outcomes post-bolus were described by the treating clinicians, and as the prescriber of the treatment, they may have preferred to perceive an improvement. One further point is that as the majority of fluid boluses were administered at day one of age, factors such as postnatal age may also have a significant effect on the parameters of physiological responses to fluids.

Published studies evaluating fluid bolus therapy in neonates are heterogeneous, and have not always included neonates with signs of haemodynamic compromise. ${ }^{12-16}$ There are no randomised studies primarily designed to examine fluid bolus compared to no fluid bolus in preterm infants with haemodynamic compromise. ${ }^{17}$ Studies in late preterm and term infants with haemodynamic compromise are limited to nonrandomised observational studies and do not report clinical benefit. ${ }^{18,19}$ A survey in Canada reported that while attitudes to the use of inotropes varied, neonatologists routinely treated suspected haemodynamic compromise in infants with a birthweight $<1500$ grams with a fluid bolus (97\%) and most commonly used $0.9 \%$ sodium chloride $(95 \%) .{ }^{20}$ Our results are consistent with this, with the majority of fluid boluses $(47 / 56 ; 84 \%)$ given to an infant to manage low blood pressure being $0.9 \%$ sodium chloride. 
Only 10 of the units participating in this study had local clinical guidelines available to guide fluid bolus use. Use of clinical guidelines, even in areas with a limited evidence base, may reduce variation in practice. ${ }^{21}$ Nevertheless, consensus is only helpful to patients if it is the right consensus, and the lack of intervention studies defining optimal fluid bolus therapy, such as indication, type, volume and rate, in preterm and term infants makes this not possible at this time. Clinicians are left to either extrapolate data from other patient groups, some now showing potential harmful effects from fluid bolus therapy in children (e.g. Fluid Expansion as Supporting Therapy (FEAST) study ${ }^{22}$ ), or rely on limited and potentially misleading physiological data to guide decisions. Interestingly, there was little regional variation observed in the use of fluid bolus therapy.

With ongoing trials examining the use of inotropes in this group of infants (http://www.neocirculation.eu and http://www.hip-trial.com), our study suggests the need for research to evaluate fluid bolus therapy. Further studies may need to explore whether infants that are more acidotic, or with higher lactate, benefit from fluid bolus therapy as might be suggested by our findings. Research needs to consider the choice of fluid as well as dose and timing. The most common fluid bolus type in our study was $0.9 \%$ sodium chloride, although this fluid is non-physiological, and concerns have been raised about the chloride load, ${ }^{23}$ which may be more important in preterm infants with less mature renal function. New studies should apply clear consensus outcomes of haemodynamic compromise and optimal monitoring ${ }^{24}$ for example development of a core outcome $\operatorname{set}^{25}$. As the FEAST trial demonstrated in children, ${ }^{22}$ our assumptions around the potential benefits of fluid bolus therapy in neonates may need careful reconsideration. 


\section{References}

[1] Osborn DA, Evans N. Early volume expansion for prevention of morbidity and mortality in very preterm infants. Cochrane Database Syst Rev. 2004.

[2] Narchi H. Is an intravenous fluid bolus of albumin or normal saline beneficial in the treatment of metabolic acidosis in a normovolaemic newborn? Arch Dis Child. 2004; 89: 884-885.

[3] Keir A, Froessler B, Stanworth S. QUESTION 2: Are intravenous fluid boluses beneficial in late preterm or term infants with suspected haemodynamic compromise? Arch Dis Child. 2016; 101: 201-202.

[4] Goldberg RN, Chung D, Goldman SL, Bancalari E. The association of rapid volume expansion and intraventricular hemorrhage in the preterm infant. J Pediatr. 1980; 96: 1060-1063.

[5] Ewer AK, Tyler W, Francis A, Drinkall D, Gardosi JO. Excessive volume expansion and neonatal death in preterm infants born at 27-28 weeks gestation. Paediatr Perinat Epidemiol. 2003; 17: 180-186.

[6] Harris PA, Taylor R, Thielke R, Payne J, Gonzalez N, Conde JG. Research electronic data capture (REDCap) - a metadata-driven methodology and workflow process for providing translational research informatics support. Journal of biomedical informatics. 2009; 42: 377-381.

[7] $\quad\{\mathrm{R}$ Core Team $\} . R$ : A language and environment for statistical computing. $\mathrm{R}$ Foundation for Statistical Computing, Vienna, Austria, 2013.

[8] Wallace BC, Dahabreh IJ, Trikalinos TA, Lau J, Trow P, Schmid CH. Closing the Gap between Methodologists and End-Users: R as a Computational Back-End. Journal of Statistical Software. 2012; 49.

[9] Ewer AK, Tyler W, Francis A, Drinkall D, Gardosi JO. Excessive volume expansion and neonatal death in preterm infants born at 27-28 weeks gestation. Paediatr Perinat Epidemiol. 2003; 17: 180-186.

[10] Mohamed A, Shah PS. Transfusion associated necrotizing enterocolitis: a meta-analysis of observational data. Pediatrics. 2012; 129: 529-540. 
[11] Rashid N, Al-Sufayan F, Seshia MM, Baier RJ. Post transfusion lung injury in the neonatal population. J Perinatol. 2012.

[12] Beverley DW, Pitts-Tucker TJ, Congdon PJ. Prevention of intraventricular haemorrhage by fresh frozen plasma. Arch Dis Child. 1985; 60: 710-713.

[13] Ekblad H, Kero P, Korvenranta H. Renal function in preterm infants during the first five days of life: influence of maturation and early colloid treatment. Biol Neonate. 1992; 61: 308-317.

[14] Gottuso MA, Williams ML, Oski FA. The role of exchange transfusions in the management of low-birth-weight infants with and without severe respiratory distress syndrome. II. Further observations and studies of mechanisms of action. J Pediatr. 1976; 89: 279-285.

[15] Lundstrom K, Pryds O, Greisen G. The haemodynamic effects of dopamine and volume expansion in sick preterm infants. Early Hum Dev. 2000; 57: 157-163. [16] The Northern Neonatal Nursing Initiative [NNNI] Trial Group. A randomized trial comparing the effect of prophylactic intravenous fresh frozen plasma, gelatin or glucose on early mortality and morbidity in preterm babies. The Northern Neonatal Nursing Initiative [NNNI] Trial Group. Eur J Pediatr. 1996; 155: 580-588.

[17] Dempsey EM, Barrington KJ. Treating hypotension in the preterm infant: when and with what: a critical and systematic review. J Perinatol. 0000; 27: 469-478. [18] Mydam J, Zidan M, Chouthai NS. A Comprehensive Study of Clinical Biomarkers, Use of Inotropic Medications and Fluid Resuscitation in Newborns with Persistent Pulmonary Hypertension. Pediatr Cardiol. 2014.

[19] Wyckoff MH, Perlman JM, Laptook AR. Use of volume expansion during delivery room resuscitation in near-term and term infants. Pediatrics. 2005; 115: 950955.

[20] Dempsey EM, Barrington KJ. Diagnostic criteria and therapeutic interventions for the hypotensive very low birth weight infant. J Perinatol. 2006; 26: 677-681. [21] Kennedy PJ, Leathley CM, Hughes CF. Clinical practice variation. Med J Aust. 2010; 193: S97-99. 
[22] Maitland K, Kiguli S, Opoka RO, et al. Mortality after fluid bolus in African children with severe infection. N Engl J Med. 2011; 364: 2483-2495.

[23] Yunos N, Bellomo R, Hegarty C, Story D, Ho L, Bailey M. Association between a chloride-liberal vs chloride-restrictive intravenous fluid administration strategy and kidney injury in critically ill adults. Jama. 2012; 308: 1566-1572. [24] Durrmeyer X, Marchand-Martin L, Porcher R, et al. Abstention or intervention for isolated hypotension in the first 3 days of life in extremely preterm infants: association with short-term outcomes in the EPIPAGE 2 cohort study. Arch Dis Child Fetal Neonatal Ed. 2017; 102: 490-496.

[25] Webbe J, Sinha I, Gale C. Core Outcome Sets. Archives of disease in childhood Education and practice edition. 2018;103:163-166.

This article is protected by copyright. All rights reserved. 


\section{Tables}

Table 1: Primary indication for fluid bolus therapy $(n=163)$ and clinical-perceived scores post-fluid bolus administration

\begin{tabular}{|c|c|c|c|c|}
\hline Main indication & $\begin{array}{l}\text { Frequency } \\
\quad(\%)\end{array}$ & $\begin{array}{l}\text { No to minor } \\
\text { improvement } \\
\text { Score } 0-2\end{array}$ & $\begin{array}{c}\text { Mild } \\
\text { improvement } \\
\text { Score 3-5 }\end{array}$ & $\begin{array}{c}\text { Major } \\
\text { improvement } \\
\text { Score 6-8 }\end{array}$ \\
\hline Low blood pressure & $56(34 \%)$ & $14(25 \%)$ & $17(30 \%)$ & $25(45 \%)$ \\
\hline $\begin{array}{l}\text { Decreased perfusion on } \\
\text { clinical assessment }\end{array}$ & $20(12 \%)$ & $1(5 \%)$ & $7(35 \%)$ & $12(60 \%)$ \\
\hline Metabolic acidosis & $20(12 \%)$ & $1(5 \%)$ & $4(20 \%)$ & $15(75 \%)$ \\
\hline Elevated lactate & $13(8 \%)$ & $2(15 \%)$ & $0(0 \%)$ & $11(85 \%)$ \\
\hline Decreased urinary output & $9(6 \%)$ & $0(0 \%)$ & $1(11 \%)$ & $8(89 \%)$ \\
\hline Blood loss/haemorrhage & $9(6 \%)$ & $1(11 \%)$ & $4(44 \%)$ & $4(44 \%)$ \\
\hline Hypovolemic shock & $6(4 \%)$ & $2(33 \%)$ & $0(0 \%)$ & $4(67 \%)$ \\
\hline $\begin{array}{l}\text { Echocardiography } \\
\text { findings (decreased } \\
\text { cardiac output) }\end{array}$ & $6(4 \%)$ & $2(33 \%)$ & $0(0 \%)$ & $4(67 \%)$ \\
\hline $\begin{array}{l}\text { Part of acute resuscitation } \\
\text { in an arrested (or peri- } \\
\text { arrest) infant }\end{array}$ & $6(4 \%)$ & $2(33 \%)$ & $3(50 \%)$ & $1(17 \%)$ \\
\hline Tachycardia & $4(3 \%)$ & $0(0 \%)$ & $1(25 \%)$ & $3(75 \%)$ \\
\hline Septic shock & $4(3 \%)$ & $0(0 \%)$ & $2(50 \%)$ & $2(50 \%)$ \\
\hline Other $\dagger$ & $10(6 \%)$ & $0(0 \%)$ & $2(20 \%)$ & $8(80 \%)$ \\
\hline
\end{tabular}

This article is protected by copyright. All rights reserved. 
†Other: volume replacement for gastric aspirate or urinary losses, polycythaemia, dehydration and renal impairment, hypovolemia, anaemia, hyperbilirubinemia, gastroschisis (unclear whether this was routine for this unit for this diagnosis, or was for another reason, such as replacement of losses or to improve perfusion). 
Table 2: Indication for fluid bolus ( $\mathrm{n}=163)$ and type of fluid used

\begin{tabular}{|c|c|c|c|c|c|}
\hline & $\begin{array}{c}0.9 \% \\
\text { sodium } \\
\text { chloride }\end{array}$ & $\begin{array}{c}\text { Packed } \\
\text { red } \\
\text { blood } \\
\text { cells } \\
\end{array}$ & $\begin{array}{l}\text { Frozen } \\
\text { plasma }\end{array}$ & $\begin{array}{l}\text { Ringers } \\
\text { lactate }\end{array}$ & Other $\neq$ \\
\hline Low blood pressure & 47 & 3 & 1 & 1 & 4 \\
\hline $\begin{array}{l}\text { Decreased perfusion on clinical } \\
\text { assessment }\end{array}$ & 18 & 1 & - & 1 & - \\
\hline Metabolic acidosis & 17 & - & - & 3 & - \\
\hline Elevated lactate & 10 & 2 & - & 1 & - \\
\hline Decreased urinary output & 8 & 1 & - & - & - \\
\hline Blood loss/haemorrhage & 5 & 3 & 1 & - & - \\
\hline Hypovolemic shock & 2 & 2 & - & 1 & 1 \\
\hline $\begin{array}{l}\text { Echocardiography findings (decreased } \\
\text { cardiac output) }\end{array}$ & 5 & - & 1 & - & - \\
\hline $\begin{array}{l}\text { Part of acute resuscitation in an arrested } \\
\text { (or peri-arrest) infant }\end{array}$ & 3 & 2 & - & 1 & - \\
\hline Tachycardia & 3 & - & - & - & 1 \\
\hline Septic shock & 3 & - & - & 1 & - \\
\hline Other† & 8 & 1 & 1 & - & - \\
\hline
\end{tabular}

†Other: volume replacement for gastric aspirate or urinary losses, polycythaemia, dehydration and renal impairment, hypovolemia, anaemia, hyperbilirubinaemia, gastroschisis (unclear whether this was routine for this unit for this diagnosis, or was for another reason, such as replacement of losses or to improve perfusion).

†Other: $4 \%$ albumin, $5 \%$ albumin, $0.45 \%$ sodium chloride

This article is protected by copyright. All rights reserved. 


\section{Figure legends}

Figure 1: Prevalence of fluid bolus therapy per admitted infant per study day.

Horizontal lines represent the proportion of infants who received a fluid bolus divided by number of potentially eligible infants during the study period. For example, for site 1: 0.021 (CI $95 \% 0.004$ to 0.037 ) or $2.1 \%$ of potentially eligible infants received a fluid bolus during study.

Figure 2: Distribution of gestational age at birth of included infants.

Figure 3: Differences in acid-base $(\mathrm{pH})$ from pre- to post- fluid bolus.

Solid grey lines represent the linear regression change in $\mathrm{pH}$ compared to initial $\mathrm{pH}$ level. The horizontal axis is the starting value and the vertical axis is the change over time. The trend line (solid grey line) indicates that the further away from "normal" the value starts, the bigger the change (closer to normal). This may due to the fluid bolus (or other factors) or other factors such as sampling and a regression to the mean.

Figure 4: Difference in lactate level from pre- to post- fluid bolus.

Solid grey lines represent the linear regression change in lactate compared to initial lactate level. The horizontal axis is the starting value and the vertical axis is the change over time. The trend line (solid grey line) indicates that the further away from "normal" the value starts, the bigger the change (closer to normal). This may due to the fluid bolus (or other factors) or other factors such as sampling and a regression to the mean. 


\section{Studies}

Australia/New Zealand 1 Australia/New Zealand 2 Australia/New Zealand 3 Australia/New Zealand 4 Australia/New Zealand 5 Australia/New Zealand 6 Australia/New Zealand 7 Australia/New Zealand 8 Australia/New Zealand 9 Australia/New Zealand 10 Australia/New Zealand 11 Australia/New Zealand 12 Canada 1

Canada 2

Canada 3

Canada 4

Canada 5

Canada 6

Canada 7

Canada 8

USA 1

USA 2

USA 3

USA 4

USA 5

USA 6

USA 7

USA 8

USA 9

Europe 1

Europe 2

Europe 3

Europe 4

Europe 5

Europe 6

Europe 7

Europe 8

Europe 9

Europe 10

Europe 11

Europe 12

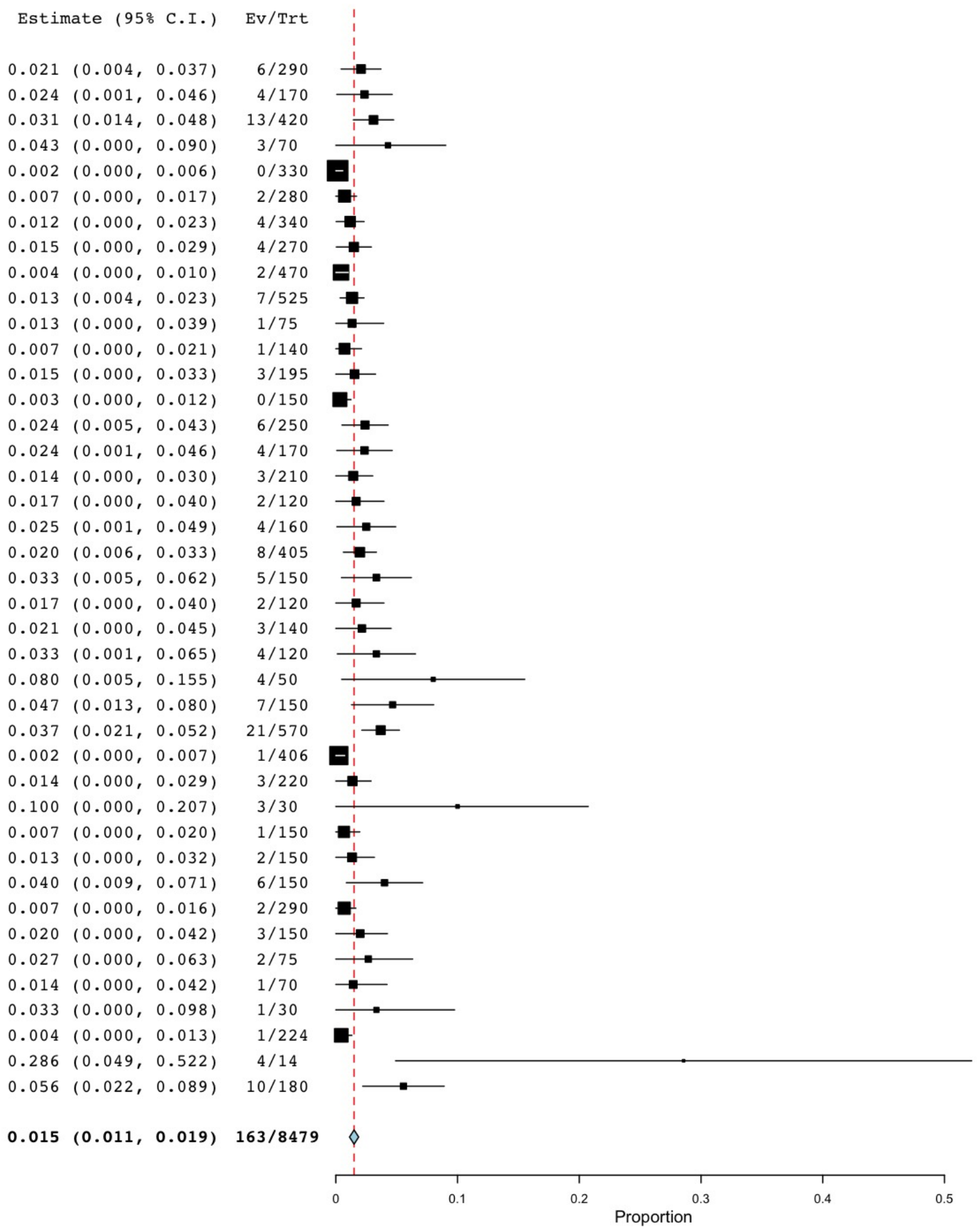

Figure_1.jpg 

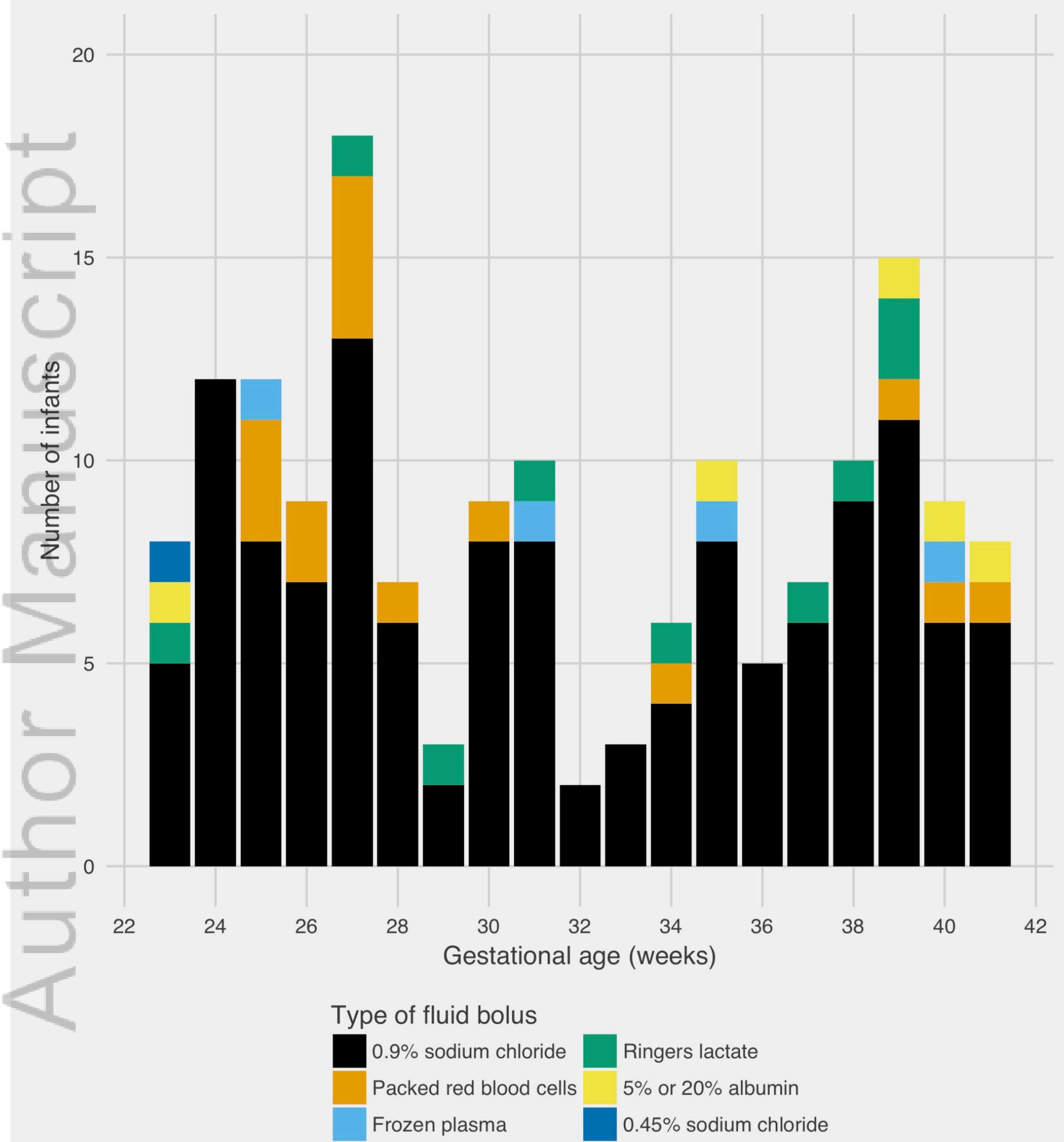

Figure_2.jpg

This article is protected by copyright. All rights reserved. 


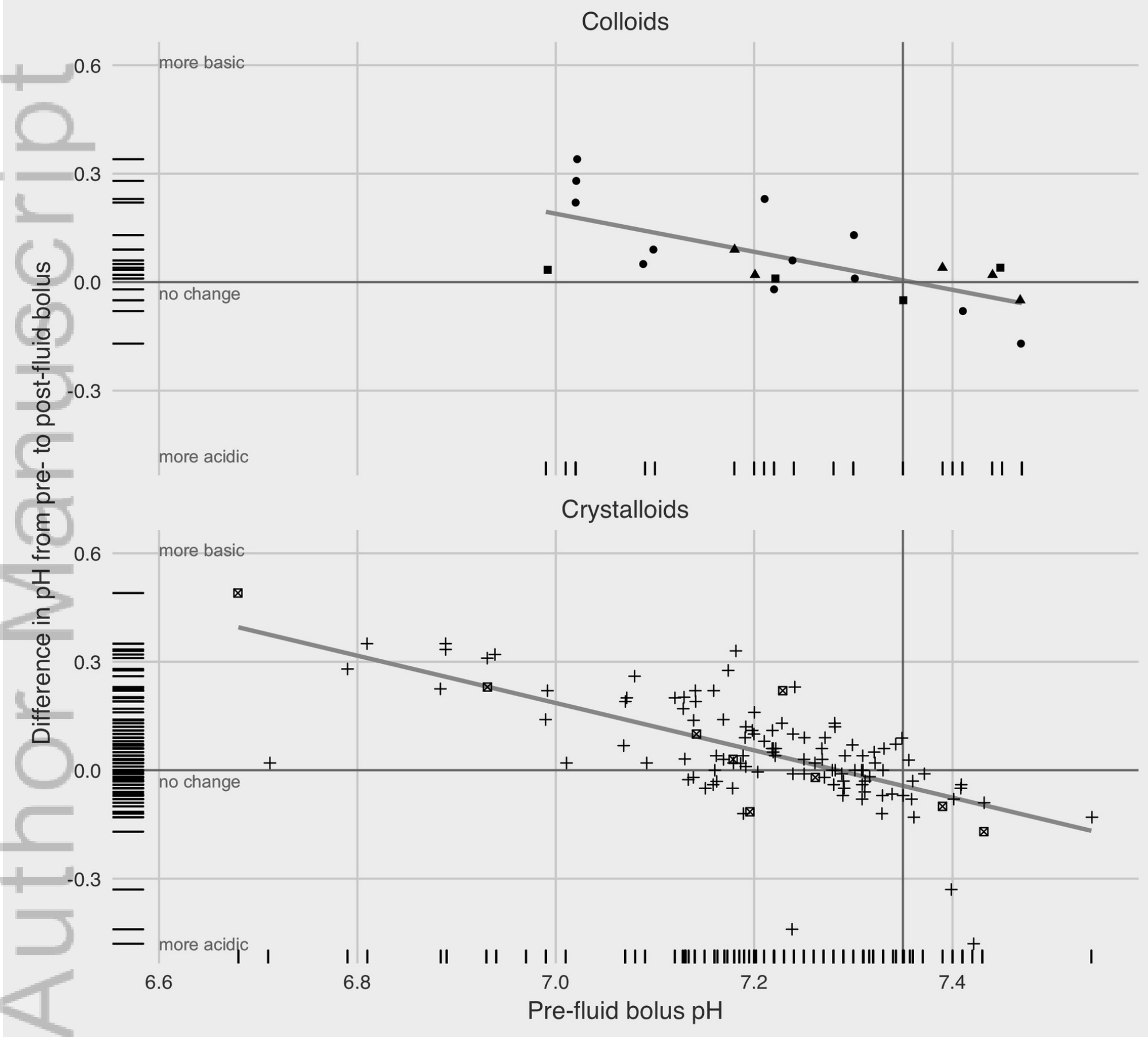

- Packed red blood cells \ $4 \%$ or $5 \%$ albumin - Frozen plasma $+0.9 \%$ saline $\otimes$ Ringers lactate

Figure_3.jpg

This article is protected by copyright. All rights reserved. 


\section{Colloids}
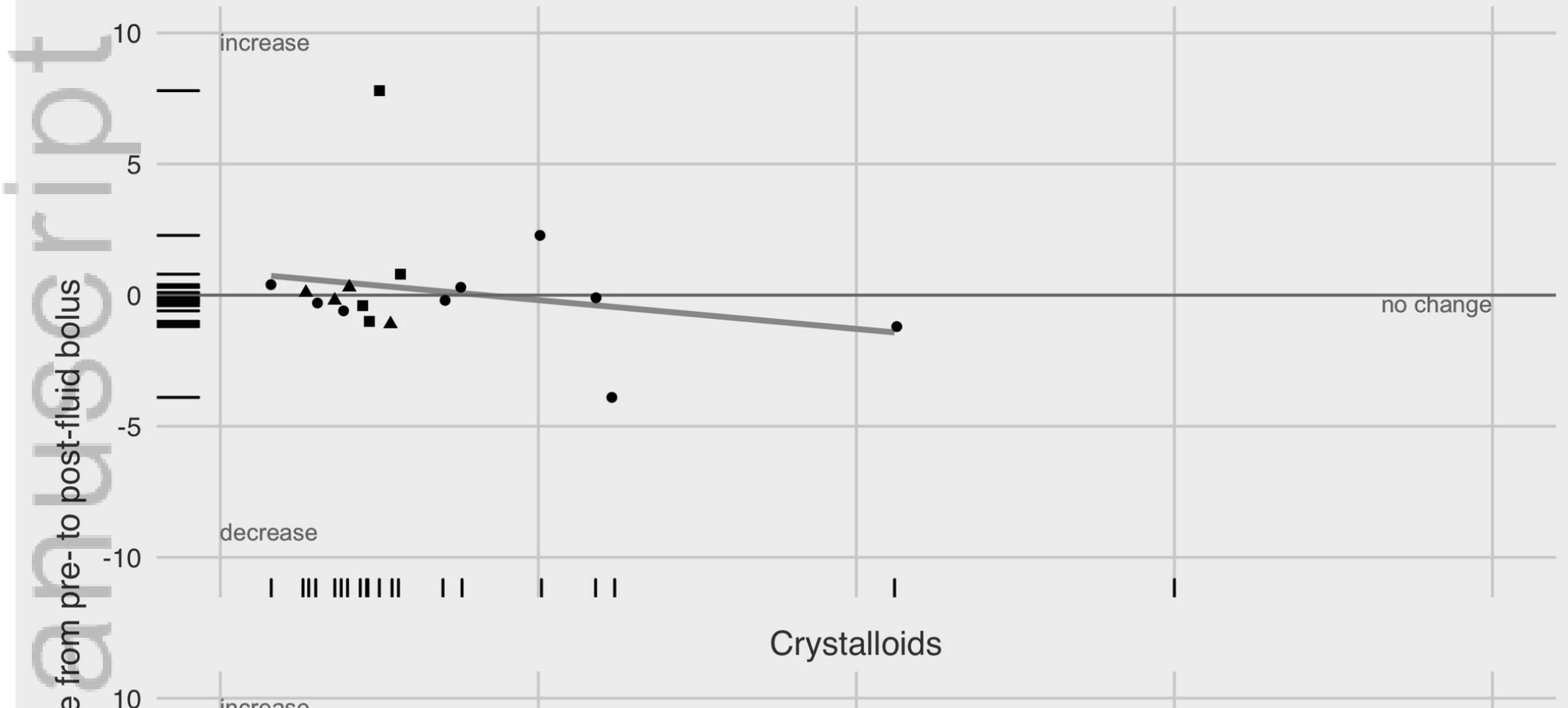

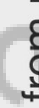

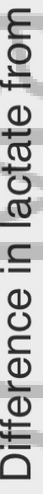
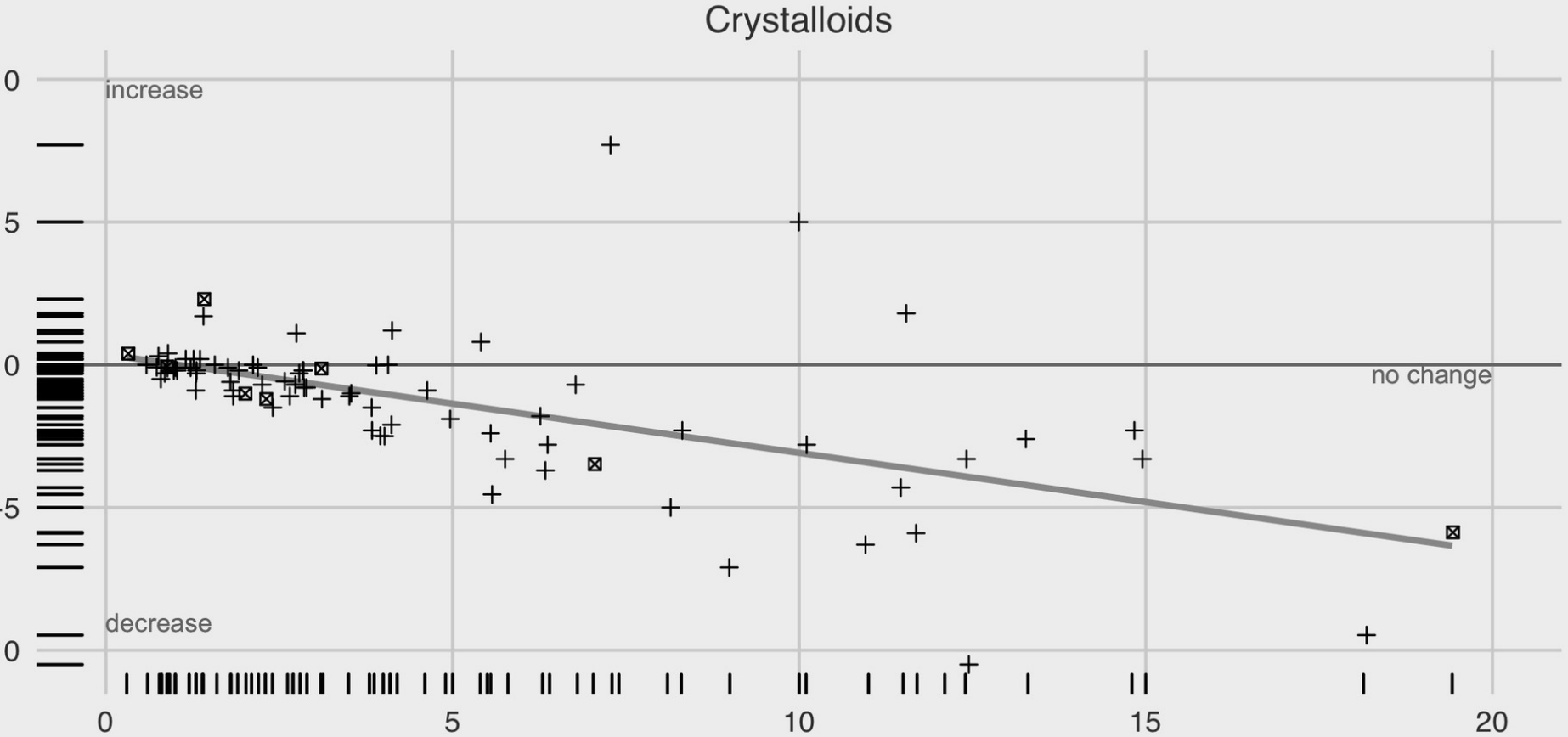

Pre-fluid bolus lactate

- Packed red blood cells $\Delta 4 \%$ or $5 \%$ albumin - Frozen plasma $+0.9 \%$ saline $\Delta$ Ringers lactate

Figure_4.jpg

This article is protected by copyright. All rights reserved. 

An international, multi-centre, observational study of fluid bolus therapy in
neonates

Type of manuscript: Original Article

Authors: AK Keir ${ }^{1,2,3}$, O Karam ${ }^{4,5}$, N Hodyl ${ }^{1,2}$, MJ Stark ${ }^{1,2}$, HG Liley ${ }^{6,7}$, PS Shah ${ }^{8,9}$ and SJ Stanworth ${ }^{10,11}$ on behalf of the NeoBolus Study Group

Affiliations:

1. Robinson Research Institute and the Adelaide Medical School, University of Adelaide

2. Department of Neonatal Medicine, Women's and Children's Hospital, North Adelaide, South Australia

3. Healthy Mothers, Babies and Children, the South Australian Medical and Research Institute, North Adelaide, South Australia

4. Pediatric Intensive Care Unit, Geneva University Hospital, Geneva, Switzerland

5. Division of Pediatric Critical Care Medicine, Children's Hospital of Richmond at VCU, Virginia Commonwealth University, Virginia, USA

6. Mater Mothers' Hospital, Mater Research, Brisbane, Queensland, Australia

7. The University of Queensland, South Brisbane, Queensland, Australia

8. Mount Sinai Hospital, Toronto, Ontario, Canada

9. University of Toronto, Toronto, Ontario, Canada

10. NHS Blood and Transplant and Department of Haematology, Oxford University Hospitals NHS Foundation Trust, Oxford, United Kingdom

11. Radcliffe Department of Medicine, University of Oxford, Oxford, United Kingdom

Corresponding author:

Dr Amy Keir

Women's and Children's Hospital

72 King William Road

North Adelaide SA 5006

AUSTRALIA

Phone: +61 881617631

Fax: +61 81617654

Email: amy.keir@adelaide.edu.au

This article is protected by copyright. All rights reserved. 


\title{
University Library
}

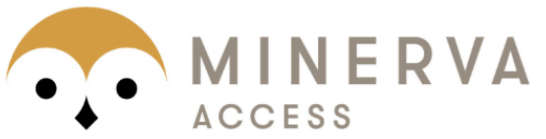

A gateway to Melbourne's research publications

Minerva Access is the Institutional Repository of The University of Melbourne

\begin{abstract}
Author/s:
Keir, AK;Karam, O;Hodyl, N;Stark, MJ;Liley, HG;Shah, PS;Stanworth, SJ;Morris, S;Carmo, KB;De Waal, K;Stubbs, M;Liley, H;Pearson, A;Campbell, H;Hunt, RW;Perkins, E;Ali, SKM;Bowen, J;Jacobs, C;Paradisis, M;Osborn, D;Greenhalgh, M;Kuschel, C;Hodyl, N;Stark, M;Keir, A;Ting, J;Barrington, K;Lapointe, A;Dow, K;Coo, H;Mukerji, A;Mohamed, A;Stavel, M;Deshpandey, A;Tucker, N;Ng, E;Diamond, C;Bourgoin, P;Bindl, L;Maria, M;De Luca, D;Dell'Orto, V;Ghirardello, S;More, K;Edmonds, L;Weaver, L;Deschmann, E;Norman, M;Thomas, O;Karlsson, J;De Luca, R;Rogdo, B;Moinho, R;Dinis, A;Wilkinson, D;Paria, A;Sola-Visner, M;Young, V;Josephson, CD;Skvarich, J;Saxonhouse, M;Poliquin, R;Courtney, S;Janssen, D;Harm, SK;Bartlett, A;Mayock, D;Lee, G
\end{abstract}

Title:

International, multicentre, observational study of fluid bolus therapy in neonates

Date:

2019-06-01

Citation:

Keir, A. K., Karam, O., Hodyl, N., Stark, M. J., Liley, H. G., Shah, P. S., Stanworth, S. J., Morris, S., Carmo, K. B., De Waal, K., Stubbs, M., Liley, H., Pearson, A., Campbell, H., Hunt, R. W., Perkins, E., Ali, S. K. M., Bowen, J., Jacobs, C. ,... Lee, G. (2019). International, multicentre, observational study of fluid bolus therapy in neonates. JOURNAL OF PAEDIATRICS AND CHILD HEALTH, 55 (6), pp.632-639. https://doi.org/10.1111/jpc.14260.

Persistent Link:

http://hdl.handle.net/11343/285077 